\title{
Pemanfaatan Bantuan Program Keluarga Harapan untuk Menyukseskan Wajib Belajar XII Tahun 2019 di Kecamatan Pusako Siak
}

\author{
Nuryanti \\ Sekolah Tinggi Agama Islam Sulthan Syarif Hasyim Siak, Indonesia \\ nuryanti@gmail.com
}

\begin{abstract}
The purpose of this study was to determine the extent to which the utilization of the Family Assistance Program (PKH )was expected to be successful in 12 years of compulsory education in the sub-district of Pusako Kabupaten Siak. The population in this study were all heads who received PKH assistance in the sub-district of Pusako kabupaten Siak. The results of the study showed that PKH assistance funds were given to succeed the 12 year compulsory education in the sub district of Pusako were very satisfying. PKH assistance was able to explain and influence the educational participation of very poor household children in the sub distrct Pusako Siakreaching 96,8 percent and 3,2 percent influenced by other variables outside of this research model. PKH assistance provision should be on target and really aimed at improving children's aducation.
\end{abstract}

Keywords: utilization , Aid Family Hope Program ( PKH), successful, compulsory education XII years

\section{A. Pendahuluan}

Program Keluarga Harapan (PKH) adalah program pemberian bantuan sosial bersyarat kepada Keluarga Penerima Manfaat (KPM) yang ditetapkan sebagai keluarga penerima manfaat Program Keluarga Harapan (PKH). PKH sudah dilaksanakan di Indonesia sejak tahun 2007, namun di Kecamatan Pusako Kabupaten Siak baru diterapkan pada tahun 2015 akhir. Program ini lebih dikenal dengan istilah Conditional Cash Transfer (CCT) atau bantuan tunai bersyarat.
Tujuan umum PKH adalah untuk meningkatkan kualitas sumber daya manusia, mengubah perilaku peserta $\mathrm{PKH}$ yang kurang mendukung upaya peningkatan kesejahteraan, dan memutus mata rantai kemiskinan antar generasi.

Secara khusus tujuan PKH adalah sebagai berikut (Pedum PKH 2008, h.12):

1. Meningkatkan kualitas kesehatan KSM

2. Meningkatkan taraf pendidikan anakanak KSM

3. Meningkatkan akses dan kualitas pelayanan pendidikan dan kesehatan, khususnya bagi anak-anak KSM 
Dengan tujuan khusus pada point kedua tersebut diharapkan dapat meningkatkan taraf pendidikan anak-anak bagi peserta PKH yaitu dengan wajib belajar XII tahun yang telah dicanangkan oleh pemerintah sekarang ini..Dalam PKH, bantuan akan diberikan kepada Rumah Tangga Sangat Miskin (RTSM) yang kategorinya sudah ditentukan oleh Badan Pusat Statistik (BPS) dan sebagai imbalannya RTSM tersebut diwajibkan untuk menyekolahkan anaknya. Rendahnya penghasilan keluarga sangat miskin menyebabkan keluarga tersebut tidak mampu memenuhi kebutuhan pendidikan untuk tingkat minimal sekalipun. Alasan terbesar untuk tidak melanjutkan sekolah ialah karena tidak ada biaya, bekerja untuk mencari nafkah, merasa pendidikannya sudah cukup dan berbagai alasan lainnya.

Komponen pendidikan dasar wajib XII tahun serta upaya mengurangi angka pekerja anak pada keluarga yang sangat miskin. Anak penerima PKH pendidikan yang berusia $7-18$ tahun belum menyelesaikan program pendidikan dasar XII tahun harus mendaftarkan diri disekolah formal atau non formal serta hadir sekurang - kurangnya $85 \%$ waktu tatap muka. Setiap anak peserta PKH berhak menerima bantuan selain PKH, baik itu Program Nasioanal maupun lokal. Pada akhirnya, implikasi positif dari pelaksanaan $\mathrm{PKH}$ harus bisa dibuktikan secara empiris sehingga pengembangan PKH memiliki bukti nyata yang bisa dipertanggung jawabkan. Untuk itu, pelaksanaan PKH juga akan diikuti dengan program monitoring dan evaluasi yang optimal.

Dalam pelaksanaannya Program Keluarga Harapan (PKH) di Kecamatan Pusako ini yang menjadi sasaran utama adalah Rumah Tangga Sangat Miskin (RTSM) yang sesuai kriteria yang telah ditetapkan yaitu ibu hamil, ibu menyusui, memiliki balita dan anak usia sekolah setingkat SD/MI,dan SMP/MTs serta SMA/Aliyah. Berdasarkan peraturan perundang-undangan $\mathrm{PKH}$ dijalankan sebagai pelaksanaan dari UU No. 40 Tahun 2004 tentang jaminan sosial nasional, UU No. 11 Tahun 2009 tentang kesejahteraan sosial, Inpres No. 3 Tahun 2010 tentang Rencana Tindak Percepatan Pencapaian Sasaran Program Pro-Rakyat, dan Perpres No. 15 Tahun 2010 tentang Percepatan Penanggulangan Kemiskinan. Merujuk pada Sistem Jaminan Sosial Nasional berdasarkan UU No. 40 Tahun 2004 tersebut, PKH menjadi sebuah model jaminan yang unik. Disatu sisi, PKH merupakan bantuan sosial yang dimaksudkan demi mempertahankan kehidupan dalam pemenuhan kebutuhan dasar terutama pendidikan dan kesehatan. Peningkatan partisipasi masyarakat juga menjadi salah satu target dalam pelaksanaan PKH ini. Untuk meningkatkan partisipasi para peserta program yaitu dengan meningkatkan angka partisipasi wajib belajar bagi anakanak peserta PKH terutama di Kecamatan Pusako Kabupaten Siak. Berdasarkan uraian tersebut di atas, maka penulis tertarik melakukan penelitian lebih lanjut dan menuangkan dalam sebuah tulisan ilmiah yang berjudul "Pemanfaatan Bantuan Program Keluarga Harapan untuk Menyukseskan Wajib Belajar XII Tahun di Kecamatan Pusako Siak”.

Penelitian Sebelumnya: Hendratno (2011) Penelitiannya yang berjudul "Pengaruh Program Keluarga Harapan (PKH) Terhadap Cakupan Imunisasi, Pemeriksaan Kehamilan, Angka Partisipasi Sekolah Dasar dan Sekolah Lanjutan Tingkat Pertama, dan Konsumsi Rumah Tangga dengan Menyajikan Hasil Analisis Dampak Awal PKH pada Sejumlah Indikator Kesehatan, Pendidikan dan Pola Konsumsi Rumah Tangga". Studi ini menggunakan rancangan ekperimen dengan melibatkan 
kelompok intervensi $\mathrm{PKH}$ dan kontrol PKH yang keduanya dipilih secaraacak. Secara keseluruhan PKH telah memberi manfaat bagi peningkatan pendidikan dan kesehatan masyarakat, sehingga perlu dipertahankan dan dikembangkan pada wilayah lainnya. Agar manfaat PKH bisa dirasakan oleh RTSM lain yang belum mendapatkan bantuan PKH.

Metode Penelitian: Jenis penelitian yang digunakan adalah metode penelitian deskriptif dengan pendekatan kualitatif. Lokasi penelitian di Kecamatan Pusako Kabupaten Siak. Data primer diperoleh dengan wawancara. Data sekunder diperoleh dengan mencari dokumendokumen yang sesuai tema penelitian. Adapun yang menjadi fokus penelitian adalah: (1) Pelaksanaan PKH di Kecamatan Pusako (2) Faktor pendukung dan faktor penghambat dalam menyukseskan wajib belajar XII tahun di kecamatan pusako bagi peserta PKH. Analisis data mengguna-kan metode analisis model interaktif yang menurut Miles dan Huberman dalam Sugiyono (2011, h.247) ada tahapan yang harus dilalui yakni: reduksi data, penyajian data, dan menarik kesimpulan.

\section{B. Pembahasan}

1. Pelaksanaan Program Keluarga Harapan (PKH) Dalam Menyukseskan wajib belajar XII tahun di Kecamatan Pusako

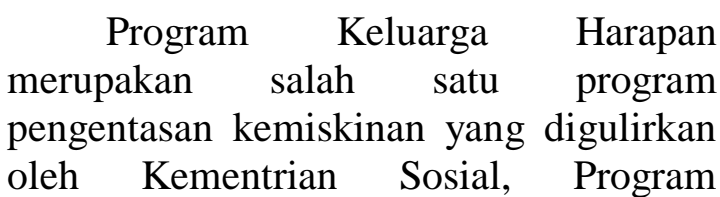
Keluarga Harapan (PKH) merupakan program bantuan yang baik dalam memberikan konstribusi sebagai upaya menurun-kan angka kemiskinan. Berkaitan dengan Program Keluarga Harapan (PKH), tujuan yang terdapat dalam pelaksanaan program ini sangat jelas dan detail. Adapun tujuan dari pelaksanaan PKH yaitu sesuai yang tercamtum dalam Pedum PKH (2015, h.10) yaitu:

1. Meningkatkan kondisi sosial ekonomi RTSM;

2. Meningkatkan taraf pendidikan anakanak RTSM;

3. Meningkatkan status kesehatan dan gizi ibu hamil, ibu nifas, dan anak di bawah 6 tahun dari RTSM;

4. Meningkatkan akses dan kualitas pelayanan pendidikan dan kesehatan khususnya bagi RTSM.

Berkaitan dengan pelaksanaan Program Keluarga Harapan di Kecamatan Pusako yaitu dengan membuat strategi dan melakukan sosialisasi. Adapun strategi pelaksanaan yang dilakukan oleh pelaksana program yaitu dengan melakukan kunjungan rutin pada setiap Rumah Tangga Sangat Miskin (RTSM) dan memantau kebutuhan sekolah bagi Anak-anak peserta $\mathrm{PKH}$, pemantauan penggunaan dana setiap kali pencairan agar sesuai dengan fungsinya, membuat sebuah inovasi berupa pengadaan baju PKH bagi para ibu ibu PKH, memantau penggunaan kartu PKH agar sesuai dengan penggunaannya, dan sering mengadakan rapat koordinasi.

Besaran bantuan yang diberikan kepada peserta PKH berdasarkan skenario besaran bantuan terdiri dari bantuan tetap, bantuan bagi RTSM pada usia tertentu, rata-rata bantuan per RTSM, bantuan minimum per-RTSM, serta bantuan maksimum per RTSM. Ada catatan penting bahwa untuk bantuan terkait kesehatan berlaku bagi RTSM dengan anak di bawah 6 tahun dan/atau ibu hamil/nifas. Besar bantuan ini tidak dihitung berdasarkan jumlah anak. Besar bantuan adalah $16 \%$ rata-rata pendapatan RTSM per tahun. Batas minimum dan maksimum adalah antara 15-25\% pendapatan rata-rata RTSM per tahun. 
Dalam setiap pelaksanaan suatu program yang menjadi salah satu unsur terpenting adalah pencapaian sebuah target. Dalam penelitian ini bardasarkan pernyataan dari pendamping ber-kaitan dengan hal tersebut target yang harus dicapai dalam pelaksanaan Program Keluarga Harapan (PKH) ini yaitu terbantunya masyarakat tidak mampu khususnya RTSM dalam me-menuhi kebutuhan hidup berkaitan dengan pendidikan anaknya. Sampai saat ini pelaksanaan PKH di Kecamatan Pusako mulai dari pertama pada akhir tahun 2015 pelaksanaan program telah terdapat peningkatan dari status pendidikan anakanak penerima bantuan PKH ini.

Peningkatan partisipasi masyarakat juga menjadi salah satu target dalam pelaksanaan PKH ini. Untuk meningkatkan partisipasi para peserta program yaitu dengan meningkatkan angka partisipasi wajib belajar bagi peserta didik. Jika partisipasi masyarakat tinggi maka secara tidak langsung akan berpengaruh pula pada peningkatan kualitas hidupnya. Oleh karena itu dengan adanya partisipasi atau peran serta masyarakat dalam pelaksanaan PKH ini akan dapat meningkatkan pembangunan yang pada akhirnya dapat mensejahterakan masyarakat khususnya masyarakan miskin.

Hasil dari evaluasi pelaksanaan Program Keluarga Harapan (PKH) bertujuan untuk memberikan bukti nyata dalam pelaksanaan program terkait dengan pembiayaan maupun pencapaian tujuan. Dengan mengetahui hasil dari pelaksanaan PKH dalam beberapa tahun ini maka pendamping akan dapat mengetahui apakah pelaksanaannya sudah berjalan dengan baik atau belum. Seperti yang dijelaskan oleh pendamping PKH di Kecamatan Pusako bahwa dalam melakukan evaluasi, sebelumnya dilakukan monitoring terhadap pelaksanaanya di wilayah $\mathrm{PKH}$ berlakukan,dari situ didapatkan beberapa beberapa hal yaitu perubahan kondisi jika dilihat dari sebelum menerima dan sesudah menerima program, adanya anggapan bahwa penerima PKH mau melakukan dan memenuhi komitmennya karena takut dengan adanya sanksi yang diberikan. Dan juga kurang pahamnya masyarakat terhadap sanksi yang disosialisasikan menyebabkan munculnya masalah yaitu penggunaan kartu yang ditidak sesuai atau melanggar kesepakatan. Jika kesepakatan di-langgar oleh peserta PKH maka sanksi yang diberikan yaitu pemotongan uang pada saat pencairan. Inilah memang seharusnya yang dilakukan bagi peserta yang melanggar komitmen karena PKH merupakan bantuan bersyarat yang menyaratkan bagi RTSM untuk mematuhi peraturan yang sudah menjadi kesepakatan bersama.

\section{Besaran Bantuan PKH di Kecamatan Pusako Kabupaten Siak untuk setiap peserta Program PKH}

\begin{tabular}{|c|c|c|c|c|c|c|}
\hline \multirow[t]{2}{*}{ Tahun } & \multicolumn{4}{|c|}{ Jumlah bantuan PKH } & \multirow{2}{*}{$\begin{array}{l}\text { Jumlah } \\
\text { Anak } \\
\text { yang } \\
\text { Putus } \\
\text { Sekola } \\
\text { h } \\
\end{array}$} & \multirow{2}{*}{$\begin{array}{c}\text { Jumlah } \\
\text { KPM } \\
\text { penerima } \\
\text { bantuan }\end{array}$} \\
\hline & $\begin{array}{l}\text { SMA/ } \\
\text { SMK/ } \\
\text { Aliyah }\end{array}$ & $\begin{array}{l}\text { SMP/MT } \\
\mathrm{S}\end{array}$ & SD/MI & $\begin{array}{l}\text { kepala } \\
\text { keluarga }\end{array}$ & & \\
\hline $\begin{array}{l}2015- \\
2016\end{array}$ & $\begin{array}{l}1.000 . \\
000 / \\
\text { anak }\end{array}$ & $\begin{array}{l}750.000 / \\
\text { anak }\end{array}$ & $\begin{array}{l}450.00 \\
0 / \\
\text { anak }\end{array}$ & & 7 & $\begin{array}{l}72 \\
\text { keluarga }\end{array}$ \\
\hline $\begin{array}{l}2017- \\
2018 \\
\end{array}$ & & & & 1.890 .000 & 5 & $\begin{array}{l}185 \\
\text { keluarga }\end{array}$ \\
\hline 2019 & $\begin{array}{l}2.000 . \\
000 / \\
\text { anak }\end{array}$ & $\begin{array}{l}1.500 .000 \\
/ \\
\text { anak }\end{array}$ & $\begin{array}{l}900.00 \\
0 / \\
\text { anak }\end{array}$ & & 3 & $\begin{array}{l}208 \\
\text { keluarga }\end{array}$ \\
\hline
\end{tabular}

Berdasarkan table diatas, dinyatakan bahwa salah satu syarat untuk mendapatkan bantuan tunai tersebut adalah anak harus mengikuti jenjang pendidikan wajib XII tahun. Jadi merupakan keharusan untuk dapat menyukseskan wajib belajar XII tahun bagi peserta penerima bantuan tunai tersebut. Apabila anak-anak yang wajib belajar tidak menyelesaikan pendidikannya maka bantuan tersebut 
akan dihentikan kepada keluarga yang akan menerima bantuan tersebut.

\section{Faktor pendukung dan penghambat dari Program Keluarga Harapan dalam menyukseskan wajib belajar XII tahun di Kecamatan Pusako}

Pelaksanaan Program Keluarga Harapan tidak terlepas dari adaya faktor pendukung. Dalam penelitian ini faktor pendukung program ini yaitu adanya koordinasi yang bagus dari aktor yang terlibat. Aktor tersebut meliputi perangkat desa, di bidang pendidikan yaitu guru/wali kelas yang harus melakukan absensi rutin agar partisipasi siswa dalam kegiatan belajar mengajar dapat terpantau,. Dengan adanya partisipasi dari pihak-pihak terkait maka program ini akan berjalan dengan baik. karena itu dukungan dari berbagai aktor inilah yang diharapkan nantinya akan lebih mampu menyukseskan Wajib belajar XII tahun bagi anak-anak peserta Program Keluarga Harapan di Kecamatan Pusako.

Selain itu, faktor pendukung pelaksanaan program adalah dukungan finansial yang mencukupi sehingga dapat menentukan kesuksesan tujuan. Dalam pelaksanaan $\mathrm{PKH}$, proses pembayaran atau pendanaan merupakan hal terpenting sebagai penentu keberhasilan. Disamping itu pendanaan menjadi hal penting sehingga diperlukan pengelolaan maupun pengawasan yang baik agar dalam pendanaannya sesuai dengan ketentuan.Oleh karena itu dengan anggaran yang cukup, pelaksanaan program keluarga harapan ini dapat berjalan dengan baik dan pada akhirnya kualitas hidup RTSM sebagai tujuan program dapat meningkat.

Sedangkan penelitian diketahui bahwa bahwa faktor penghambat merupakan sebuah acuan bagi pelaksanaan program sebagai hasil evaluasi. Adapun yang menjadi faktor peng-hambat dalam pelaksanaan $\mathrm{PKH}$ ini yaitu kurang pahamnya RTSM terhadap sanksi yang di-berikan. Hal ini dibuktikan dengan penggunaan kartu PKH diluar fungsi yaitu digunakan sebagai kartu jaminan. Sehingga ketika melakukan pencairan peserta PKH mengalami kesulitan pada saat pencairan dana.kemudian beberapa diantara mereka masih menggunakan data lama ebagai data baru agar peserta PKH tetap mendapatkan uang tunai.

Kesimpulan :Dari penelitian yang telah dilakukan peneliti tentang pemanfatan bantuan Program Keluarga Harapan (PKH) dalam menyukseskan wajib belajar XII tahundi Kecamatan Pusako dapat disimpulkan bahwa pelaksanaan Program Keluarga Harapan (PKH) di Kecamatan Pusako yaitu sangat bermanfaat untuk masyarakat tidak mampu khususnya RTSM dalam memenuhi kebutuhan hidup berkaitan dengan pendidikan anaknya untuk menuntaskan wajib belajar XII tahun. Hasil Evaluasi membuktikan bahwa penerima PKH mau melakukan dan memenuhi komitmennya dikarenakan takut dengan adanya sanksi yang diberikan. Berdasarkan data yang ada diketahui bahwa setiap tahun nya peserta PKH mengalami penurunan. Terbukti dengan menurunnya jumlah anak-anak yang putus sekolah dari peserta $\mathrm{PKH}$ tersebut.

\section{Daftar Pustaka}

Pedoman Umum Pelaksanaan Program Keluarga Harapan (PKH) tahun 2015. Jakarta, Kementrian Sosial RI.Kusuma Hadi. (2013) Ribuan Warga Sangat Miskin di Kabupaten Kediri

Belum Merasakan Program PKH. [Internet] Available from: $<$ http://www.andikafm.com/news/d 
etail/4493/1> [Accessed: 7 Juni 20013].

Ndraha, Taliziduhu. (1999) Pengantar Teori Pengembangan Sumber Daya Manusia. Jakarta, Rineka Cipta.

Sedarmayanti (2001) Sumber Daya Manusia dan Produktivitas Kerja. Bandung, Mandar Maju.

Siagian, Sondang P. (2003). Administrasi Pembangunan, Konsep, Dimensi dan Strateginya. Jakarta, Gunung Agung.

Sugiyono (2011) Metode Penelitian Kuantitatif, Kualitatif dan $R \& D$. Bandung, Alfabeta.

Suharto, Edi. (2005) Membangun Masyarakat Memberdayakan Rakyat, Kajian Strategis Pembangunan Kesejahteraan Sosial dan Pekerjaan Sosial. Bandung, Refika Aditama.

Sumaryadi, I. Nyoman. (2010) Sosiologi Pemerintahan. Dari Perspektif Pelayanan, Pemberdayaan, Interaksi, dan Sistem Kepemimpinan Pemerintahan. Indonesia. Jakarta, Ghalia Indonesia.

Suryono, Agus. (2004) Pengantar Teori Pembangunan. Malang, UM Press.

Todaro, Michael, P. (2004) Pembangunan Ekonomi Dunia ke-3 Jilid1 Edisi 8. Jakarta, Erlangga.

Zainun, Buchori. (1993) Manajemen Sumber Daya Manusia, Cet. II. Jakarta, Gunung Agung. 